\title{
Integrating Characterization of Smallholders' Feeding Practices with On-Farm Feeding Trials to Improve Utilization of Crop Residues on Smallholder Farms
}

\author{
B. O. Kashongwe, ${ }^{1,2}$ B. O. Bebe, ${ }^{1}$ P. A. Ooro, ${ }^{3}$ P. K. Migwi, ${ }^{1}$ and T. A. Onyango ${ }^{4}$ \\ ${ }^{1}$ Department of Animal Sciences, Faculty of Agriculture, Egerton University, P.O. Box 536, Egerton 20115, Kenya \\ ${ }^{2}$ Institut Supérieur des Techniques Médicales (ISTM-Bukavu), P.O. Box 3036, Bukavu, South Kivu, Democratic Republic of the Congo \\ ${ }^{3}$ Kenya Agricultural and Livestock Research Organization (KALRO), Njoro 20107, Kenya \\ ${ }^{4}$ Kenya Agricultural and Livestock Research Organization (KALRO), P.O. Box 25, Naivasha 20117, Kenya
}

Correspondence should be addressed to B. O. Kashongwe; okashongwe@gmail.com

Received 21 November 2016; Accepted 23 February 2017; Published 12 March 2017

Academic Editor: Claus A. Soerensen

Copyright (C) 2017 B. O. Kashongwe et al. This is an open access article distributed under the Creative Commons Attribution License, which permits unrestricted use, distribution, and reproduction in any medium, provided the original work is properly cited.

\begin{abstract}
This study characterized wheat straw feeding practices in smallholder farms using cross sectional survey and the results informed the design of an experiment to improve the nutritive value of wheat straw with urea and yeast culture treatment. Three diets tested in 49 days' feeding trial were farmers' rainy season feeding practice (FP), addition of urea to wheat straw at the time of feeding (USWS), and 14 days' incubation of straw with urea (UTWS). Yeast culture ( $15 \mathrm{~g} /$ day) was mixed with commercial dairy meal at the point of feeding. Survey data identified farmers' strategies in utilizing crop residues of which most important were improving storage facility $(77.6 \%)$, adding molasses $(54.5 \%)$, and buying a shredding machine (45.1\%). On-farm feeding trial showed that intake was higher for UTWS than $(p<0.05)$ for USWS while milk yield was higher with FP than $(p<0.005)$ with UTWS or USWS but not different $(p \geq 0.05)$ between UTWS and USWS. Results imply that farmers feeding practices of crop residues may be improved for dairy cows' feeding and therefore UTWS could be used to support maintenance and milk production during dry season. Improving farmers feed storage facilities and training on incubation of wheat straw for dairy cattle feeding were recommended.
\end{abstract}

\section{Introduction}

Smallholder dairy farmers in the Kenya highlands are producing milk under conditions of feed scarcity because of competition for land that restricts access to adequate grazing pastures and fodder production. The available on-farm feed is estimated at less than $5 \mathrm{Kg}$ of the dry matter per head per day [1], which is an amount that cannot even support maintenance requirements of a cow producing 10 liters of milk a day. This reflects feed scarcity which worsens during dry season when the feed available in abundance is crop residues, but farmers underutilise this feed resource because they face challenges in improving the nutritive value. The feed fed is characterized by high degree of lignification high cell-wall content, low organic matter digestibility $(<55 \%)$, low crude protein $<(8 \%)$, and negligible available protein
(3 to 4\%) and low content of soluble sugars [2], deficiency in calcium and phosphorus minerals and vitamins [3], and low metabolizable energy (5 to $8 \mathrm{MJ} / \mathrm{kg} \mathrm{DM}$ ) [4]. These nutritional attributes limit animal dry matter intake to levels that are inadequate to meet the production requirements.

There are several approaches to improve the nutritive value of crop residues for dairy cattle feeding including improved handling and processing to increase palatability, voluntary intake, and digestibility to release nutrients to animals. Addition of yeast culture (Saccharomyces cerevisiae) and treatment of straw with urea [5] are viable for improving the nutritive value of crop residues, but farmers are yet to adopt their utilization though.

Urea supplementation and/or treatment provide a viable option to improving the feeding value of crop residues. 
Urea-ammoniation of crop residues releases ammonia after dissolving in water. For practical use by farmers, urea is a source of nitrogen which is deficient in the straw [6] and is safer than using anhydrous or aqueous ammonia.

The use of yeast culture (Saccharomyces cerevisiae) has been introduced to ruminant herbivores feeding on fibrous roughages because yeast culture action can utilize part of free sugar in the rumen and also create a fermentation shift due to rapid degradation of fibrous material. Furthermore, the yeast can secrete some metabolites that are useful for other rumen microorganisms. Yeast culture contains B vitamins, amino acids, and organic acids, particularly malate, which stimulates growth of other rumen bacteria that digest the cellulose [7].

A systematic study was therefore designed to exploit the potential nutritional advantage of feeding crop residues treated with urea and molasses with addition of yeast culture for ruminant animals. The study characterized wheat straw feeding practices in smallholder mixed farms and used the results to design feeding trial to improve the nutritive value of wheat straw with urea and yeast culture treatment and then selected the most promising diet to formulate a wheat straw based diet for on-farm feeding trial. The study aimed to (i) understand how farmers utilize crop residues in feeding dairy cattle and (ii) test whether wheat straw treatment with urea and being fortified with yeast culture can improve nutritive and subsequently intake and milk yields in dairy cows under smallholder dairy feeding practices.

\section{Materials and Methods}

\subsection{Cross Sectional Survey of Wheat Straw Feeding Practices in Smallholder Dairy Farms}

2.1.1. Description of Study Areas. This study used data from farm cross sectional surveys in wheat-dairy farming systems in Uasin Gishu and Nakuru Counties of Kenya because of the dominance of small and large scale wheat growing, smallholder dairy farming, and prominence of wheat straw feeding practice to cattle during dry seasons. A wheatdairy farming system has been described by Jaetzold and Schmidt [8] in which the authors classify Uasin Gishu as Wheat/Maize-Barley Zone within the agroecological zone Lower Highland (LH3). The area has average temperature of about $17.5^{\circ} \mathrm{C}$ during the wheat growing season and bimodal rainfall distribution peaking in April for the long rains and in August for the short rains. The medium maturing wheat varieties are grown during the short rains. In Nakuru County, sampling was in Njoro area which has annual bimodal rainfall ranging from 900 to $1020 \mathrm{~mm}$ and is classified as Wheat/Maize-Pyrethrum Zone in Lower Highland (LH2) and Upper Highland (UH2) farming systems. The Upper Highland 2 is Wheat-Pyrethrum Zone where maize is affected by cold weather and frost.

2.1.2. Sampling Procedure and Data Collection. A random cross sectional survey of farms was conducted in selected locations (Uasin Gishu and Njoro) based on a priori information obtained from the local Livestock Extension Office. From a list of smallholder farmers growing wheat and keeping dairy cattle, a sample of 220 was randomly selected to administer a structured questionnaire on wheat straw handling, processing, and feeding to dairy cows.

2.1.3. Data Processing and Statistical Analysis. The obtained cross sectional survey data on wheat straw feeding practices was processed using descriptive statistics in SAS software to describe patterns of wheat straw feeding practices by smallholder farmers. Inferential statistics with chi-square test statistics was applied to differentiate wheat straw handling, processing, and feeding by production systems (free, semizero, and zero grazing) and seasons (rainy, dry, and drought).

\subsection{Researcher Designed and Farmer Managed Feeding Trial}

2.2.1. Diets Preparation. Three treatment diets were tested during the on-farm validation study and these included farmers' practice (FP), urea-supplemented wheat straw (USWS), and urea-treated wheat straw (UTWS). The diets were prepared in situ at the farms where the studies were conducted except the wheat straw which was shredded on station using tractor mounted shredder and transported to the farms. During a period of seven (7) days, the current farmers' feeding practice (FP) was administered by the farmer but monitored by the project data clerks at each of the six collaborating farms. This was because animal performance under farmers' practice was to be compared with improved wheat straw basal diets. Records on animal breed, feed offered, intake levels, and milk yield were collected.

Urea-supplemented wheat straw (USWS) consisted of $10 \mathrm{~kg}$ DM shredded $( \pm 50 \mathrm{~mm})$ wheat straw (i.e., $11 \mathrm{~kg}$ on as feed basis at $910 \mathrm{~g} / \mathrm{Kg}$ ); then 200 grams of urea, $200 \mathrm{~g}$ ruminant salt, and $2 \mathrm{~kg}$ molasses were dissolved in $5 \mathrm{~L}$ of water in a bucket. The liquid mixture was sprinkled on the shredded wheat straw spread on a polythene sheet and then thoroughly mixed in readiness for feeding. Dairy meal $(2 \mathrm{~kg} /$ day $)$ was supplemented during feeding time. In the morning feeding, dairy meal $(1 \mathrm{Kg})$ was mixed with 15 grams of yeast culture and fed to the cow as a priority. Thereafter, the basal diet of urea-supplemented wheat straw was offered to the cow free choice. The estimated nutritive value of USWS is given in Table 1 .

The urea-treated wheat straw (UTWS) basal diet was prepared with urea $(400 \mathrm{~g})$ dissolved into $5 \mathrm{~L}$ of water and then sprinkled on shredded $( \pm 50 \mathrm{~mm})$ wheat straw $(10 \mathrm{~kg} \mathrm{DM})$ spread on a polythene sheet. After ensuring a thorough mixing of ingredients, the diet was transferred into a large airtight polythene bag. The mixture was kept for a minimum of 14 days so as to give ample time for urea to act on the straw $[9,10]$. After 14 days the bags were opened and straw was ready for feeding but prior to feeding the urea-treated straw was aerated to remove any unreacted ammonia. Dairy meal was offered during milking time at rate of $2 \mathrm{~kg} /$ day/cow as supplementary feed. The ingredients and estimated chemical composition of UTWS are shown in Table 2.

2.2.2. Experimental Design and Statistical Analysis. Six farmers among those sampled during cross sectional survey were 
TABLE 1: Proportional contribution and estimated chemical composition of ingredients in USWS diet.

\begin{tabular}{lccccc}
\hline Item & Proportion & $\mathrm{ME}(\mathrm{MJ} / \mathrm{Kg})$ & $\mathrm{CP}(\%)$ & $\mathrm{Ca}(\%)$ & $\mathrm{P}(\%)$ \\
\hline Wheat straw & 69.86 & 4.5 & 3.35 & 0.26 & 0.03 \\
Dairy meal & 13.97 & 1.47 & 2.24 & - & - \\
Molasses (+salt) & 13.97 & 0.68 & 1.19 & 0.02 & - \\
Yeast culture & 0.15 & - & 0.05 & - & - \\
Urea & 2.10 & - & 5.90 & - & - \\
Total & 100 & 7.66 & 12.73 & 0.28 & 0.04 \\
\hline
\end{tabular}

ME: metabolizable energy, CP: crude protein, Ca: calcium, and P: phosphorus.

Source: Kashongwe et al. [20]; FAO [25].

TABLE 2: Proportional contribution and estimated chemical composition of ingredients in UTWS diet.

\begin{tabular}{lccccc}
\hline Item & Proportion & $\mathrm{ME}(\mathrm{MJ} / \mathrm{Kg})$ & $\mathrm{CP}(\%)$ & $\mathrm{Ca}(\%)$ & $\mathrm{P}(\%)$ \\
\hline Wheat straw & 69.37 & 4.49 & 3.33 & 0.26 & 0.03 \\
Dairy meal & 13.87 & 1.47 & 2.22 & 0.00 & - \\
Molasses (+salt) & 13.87 & 1.68 & 1.18 & 0.02 & - \\
Yeast culture & 0.15 & 0.00 & 0.05 & - & - \\
Urea & 2.77 & 0.00 & 7.82 & - & - \\
Total & 100 & 7.64 & 14.59 & 0.28 & 0.04 \\
\hline
\end{tabular}

ME: metabolizable energy, CP: crude protein, Ca: calcium, and P: phosphorus.

Source: Kashongwe et al. [20]; FAO [25].

selected on the criteria of owning at least three milking cows, willingness to fully dedicate 2 milking cows to the experiment to the end, and acceptance of modest compensation for use of the animals. Extension officers selected 10 farms of which the project team visited and interviewed the farmers and narrowed selection to 3 farms in Njoro and 3 in Rongai.

During the experiment, one farmer did not provide consistent data and, therefore, was not included in the study, making the total number of cows used 10 instead of 12 . Selected cows were allocated in a three-period crossover design, following a sequence of dietary treatment administration of $T_{1}$ (FP), $T_{2}$ (USWS), and $T_{3}$ (UTWS). There was a 14 days' adaptation between two diets administration. Milking was done twice a day in the morning $(0600 \mathrm{hr})$ and in the afternoon (at $1700 \mathrm{hr}$ ). Milk yield was weighed and recorded every day throughout the study period.

Data was analyzed using MIXED procedure of SAS [11] which fitted the statistical model adapted from Yarandi [12]:

$$
Y_{i j k}=\mu+\alpha_{i}+\beta_{j(i)}+\gamma_{k}+\alpha \gamma_{i k}+\varepsilon_{i j k},
$$

where $Y_{i j k}$ is the response due to subject $k$, treatment $j$, and period $i ; \mu$ is the overall mean; $\alpha_{i}$ is the fixed effect due to the dietary treatment, assuming that $\sum \alpha_{i}=0 ; \beta_{j(i)}$ is the random effect due to subject $I$ nested within the treatment, $\beta_{j(i)} \sim N\left(0, \sigma^{2} \beta\right) ; \beta_{j(i)}$ are independent; $\gamma_{k}$ is the fixed effect due to the period $k, \sum \gamma_{k}=0 ; \alpha \gamma_{i k}$ is the fixed effect of interaction due to treatment $i$ and period $k, \sum \alpha \gamma_{i k}=0 ; \varepsilon_{i j k}$ is the random error component, $\varepsilon_{i j k} \sim N\left(0, \sigma^{2} \varepsilon\right)$.

\section{Results}

3.1. Characterization of Crop Residues Feeding Practices. Table 1 presents information on the use of crop residues in the four major production systems and by seasons. These results indicate that maize stover and bean husks were the most utilized crop residues (56.8\% and 82.7 , resp.) in semi-zerograzing system, while wheat straw $(37.3 \%$ and $61.2 \%$, resp.) and sorghum straw $(23.9 \%$ and $42.4 \%$, resp.) were the most utilized in the free grazing and in tethering systems. Farmers reported using wheat straw (59.7\%), maize stover (58.0\%), and beans husks (64.0\%), mainly in dry season (Table 3).

Shredding of crop residues was the most used strategy by those farmers practicing tethering and paddocking (63.4\%), while supplementation with concentrates was the most used by those practicing zero grazing (62.5\%) (Table 4$)$.

The constraints in utilizing crop residues farmers identified were high cost of milling/shredding (70\%) and low palatability of crop residues to animals (54.7\%) and lack of storage facilities (35.6\%). The strategies that farmers have applied to enable better utilization of crop residues were building storage facilities (77.6\%) and adding molasses (54.5\%) to improve palatability and use additives (30\%) which farmers explained to be for increasing milk yield from feeding of crop residues (31.1\%) (Table 5).

3.2. Researcher Designed and Farmer Managed Feeding Trial. USWS diet had the lowest effect (Table 6) on dry matter intake 
TABLE 3: Use of crop residues within the production systems and seasons.

\begin{tabular}{|c|c|c|c|c|}
\hline \multirow[b]{2}{*}{ Production systems } & \multicolumn{4}{|c|}{ Crop residues } \\
\hline & $\begin{array}{l}\text { Maize stover } \\
(N=145)\end{array}$ & $\begin{array}{c}\text { Beans husks } \\
(N=145)\end{array}$ & $\begin{array}{l}\text { Wheat straw } \\
(N=145)\end{array}$ & $\begin{array}{c}\text { Sorghum straw } \\
\quad(N=145)\end{array}$ \\
\hline \multicolumn{5}{|l|}{ Production systems } \\
\hline Free grazing (\%) & 16.95 & 2.47 & 37.31 & 23.91 \\
\hline Tethering and paddocking (\%) & 21.19 & 11.11 & 61.19 & 42.39 \\
\hline Semi-zero grazing & 56.78 & 82.72 & 0.00 & 32.61 \\
\hline Zero grazing (\%) & 5.08 & 3.70 & 1.49 & 1.09 \\
\hline Chi-square & $19.41^{*}$ & $86.13^{*}$ & $63.78^{*}$ & $46.94^{*}$ \\
\hline \multicolumn{5}{|l|}{ Season of feeding } \\
\hline Dry season & 57.98 & 64.04 & 59.72 & 35.00 \\
\hline Rainy season & 2.52 & 3.37 & 0.00 & 0.00 \\
\hline Throughout the year & 39.50 & 32.58 & 40.28 & 65.00 \\
\hline Chi-square & $0.28(N S)$ & 6.35 (NS) & $4.18(N S)$ & $6.84^{*}$ \\
\hline
\end{tabular}

${ }^{*}$ Significant at $p<0.05$. NS: not significant at $p>0.05$.

and farmers' practices (FP) the highest effect on milk yield. UTWS showed better milk yield than USWS but both were still lower than FP while UTWS and USWS were not $(p>$ 0.05 ) any different in effects.

\section{Discussion}

Farm survey results revealed predominance feeding of wheat and sorghum straws during the dry season under both free-grazing and zero-grazing systems which corroborates seasonal variation in the use of crop residues observed by McDowell [13]. The author explained that seasonal variation in the use of crop residues was a result of the scarcity of pastures due to drought but also to the land size for which production of human food and livestock feed competes.

In Kenya, the use of maize stover as animal feed can be related to the fact that maize is a staple food crop grown in the highlands where the study was performed [14]. To overcome the constraints of feeding crop residues to livestock, including low palatability, lack of storage facilities, and cost of shredding, farmers used additives, improved water storage facilities, and purchased shredding machine.

To improve utilization of crop residues, farmers were manually chopping, supplementing with concentrates and forages, mechanically shredding, and applying some chemical treatment. Shredding helps reducing farmers' work load in manually chopping crop residues; this usually leads to unequal particle sizes and high level of refusals. Small particle size attained during shredding is done to reduce wastage, selection, energy used chewing and facilitates improvement of crop residues' value. However, particle sizes smaller than $0.18 \mathrm{~cm}$ have negative effects amount of buoyant digesta, saliva production, rumen $\mathrm{pH}$, activity of cellulolytic bacteria, and acetate to propionate ration $[15,16]$. Therefore, particle sizes of 0.79 to $1.9 \mathrm{~cm}$ are recommended. The choice of supplementing straws with forages and concentrates has been reported to have a positive impact on animal productivity [17] while chemical treatment and ensiling have proven positive effect on digestibility and milk yield in dairy cows $[10,18,19]$.

It was identified from the survey results of feeding practice that improving nutritive value of the feed resource posed a challenge to farmers in utilizing the feed resource effectively. Therefore, a feeding trial was designed to identify suitable interventions to improve nutritive value of crop residues for better utilization. Results have been reported in Kashongwe et al. [20].

On-farm trial showed that milk yield from the animals fed UTWS was lower than FP, which corroborates with findings by Teshome [21] and suggests that this diet is suitable for dry season feeding to cope with feed scarcity rather than for supporting high milk yields. Results from this study showing higher values for UTWS compared to USWS are in agreement with some previous studies including Cloete and Kritzinger [22], Williams et al. [23], and Chenost [24]. This may be because urea treatment (UTWS) not only increases the nitrogen content of wheat straw as in USWS but also contributes to breaking down the lignocellulose bond of the straw to partially avail hemicellulose for rumen degradation. Therefore, improvement in digestibility and milk production of wheat straw is observed [25].

Dairy cows had higher dry matter intake when fed on urea-treated wheat straw basal diet fortified with yeast culture than when fed on USWS fortified with YC. It can therefore be recommended as a dry season feed to maintain dairy cows. Further studies should investigate the ways of improving milk 


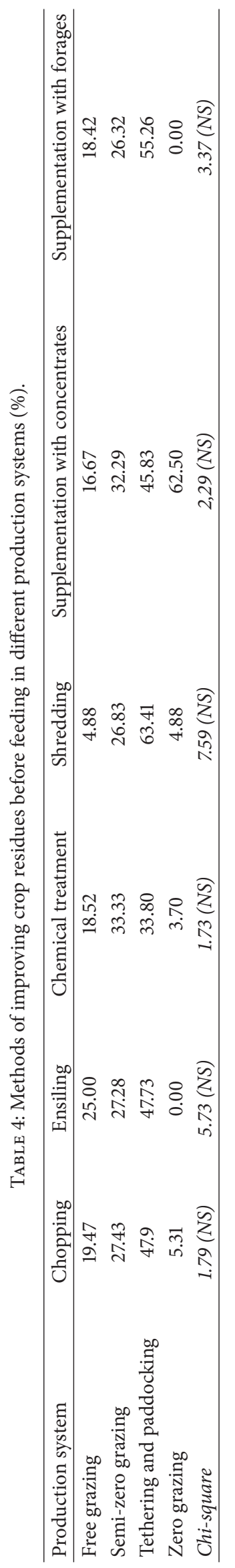


TABLE 5: Constraints faced by farmers $(n=142)$ in feeding crop residues and cited strategies to address them $(\%)$.

\begin{tabular}{|c|c|c|c|c|c|}
\hline Strategies & Lack storage facilities & Low palatability & Milling expense & Reduced milk yield & Others \\
\hline Adding molasses & 0.00 & 54.50 & 12.80 & 0.00 & 12.40 \\
\hline Build storage facilities & 77.60 & 0.00 & 8.40 & 3.80 & 32.00 \\
\hline Buy milling machine & 3.50 & 0.00 & 45.10 & 0.00 & 9.20 \\
\hline Incorporate additives & 0.00 & 30.00 & 4.90 & 31.10 & 7.00 \\
\hline Others & 6.80 & 40.80 & 28.30 & 4.70 & 87.90 \\
\hline Total for constraints & 35.6 & 54.7 & 70.0 & 19.6 & 80.1 \\
\hline
\end{tabular}

TABLE 6: Effect of UTWS and USWS basal diets supplemented with yeast culture on dry matter intake and milk yield of dairy cows.

\begin{tabular}{lcc}
\hline Diets & DMI & Milk yield $(\mathrm{Kg})$ \\
\hline FP & - & $6.92 \pm 0.57^{\mathrm{a}}$ \\
USWS & $10.74 \pm 0.86^{\mathrm{b}}$ & $3.95 \pm 0.64^{\mathrm{b}}$ \\
UTWS & $11.76 \pm 0.86^{\mathrm{a}}$ & $4.46 \pm 0.64^{\mathrm{b}}$ \\
\hline
\end{tabular}

Means within a column with different letter superscript differ at $5 \%$.

yield with urea-treated wheat straw supplemented with yeast culture and possibly with preformed protein sources.

\section{Conclusions and Recommendations}

Farmers utilized wheat straw alongside maize stover and bean husks in the semi-zero grazing but faced challenges in improving low palatability for which they used molasses and improved the nutritive value by shredding and supplementation with concentrates. However, these strategies do not adequately improve digestibility and intake of crop residues. Hence, further studies should investigate the ways of improving crop residues with particle size reduction and chemical and biological interventions. Decision makers should help farmers to get adequate facilities to harvest, store, and improve crop residues by animals so as to raise their household incomes and food security.

\section{Conflicts of Interest}

The authors declare that they have no conflicts of interest.

\section{Acknowledgments}

The authors wish to acknowledge the financial support from East African Agricultural Productivity Project (EAAPP). The same goes to Kenya Agricultural and Livestock Research Organization (KALRO), Njoro, and Naivasha Centres; Egerton University for providing the facilities and supervision; and field livestock production extension staff from both Njoro and Rongai of Nakuru County for mobilizing farmers and supervising the on-farm trials.

\section{References}

[1] H. L. Potter, Inventory of Feed Resources for the Smallholder Farmer in Kenya, Kenya Agricultural Research Institute (KARI), 1988.
[2] R. A. Leng, "Factors affecting the utilization of 'poor-quality' forages by ruminants particularly under tropical conditions," Nutrition Research Reviews, vol. 3, no. 1, pp. 277-303, 1990.

[3] A. R. Staniforth, Cereal Straw, Clarendon Press, Oxford, UK, 1979.

[4] C. C. Balch, "The potential of poor quality agriculture and agricultural roughage for animal feeding," in New Feed Resources: Proceedings of a Technical Consultations, FAO, Rome, Italy, 1976.

[5] F. P. Plata, G. D. Mendoza, J. R. Bárcena-Gama, and S. S. Gonzalez, "Effect of a yeast culture (Saccharomyces cerevisiae) on neutral detergent fiber digestion in steers fed oat straw based diets," Animal Feed Science and Technology, vol. 49, no. 3-4, pp. 203-210, 1994.

[6] G. M. J. Horton and H. H. Nicholson, "Nitrogen sources for growing cattle fed barley and either wheat straw or dehydrated alfalfa," Journal of Animal Science, vol. 52, no. 5, pp. 1143-1149, 1981.

[7] E. S. Callaway and S. A. Martin, "Effects of a Saccharomyces cerevisiae culture on ruminal bacteria that utilize lactate and digest cellulose," Journal of Dairy Science, vol. 80, no. 9, pp. 2035-2044, 1997.

[8] R. Jaetzold and H. Schmidt, Farm Management Handbook of Kenya, vol. 2, part B, Central Kenya. Ministry of Agriculture, Nairobi, Kenya, 1983.

[9] T. Smith, On-Farm Treatment of Straws and Stovers with Urea, University of Reading, Reading, UK, 2001.

[10] FAO, "Successes and failures with animal nutrition practices and technologies in developing countries," in Proceedings of the FAO Electronic Conference, H. P. S. Makkar, Ed., FAO Animal Production and Health Proceedings. no. 11, p. 30, Rome, Italy, September 2010.

[11] SAS Institute Inc, SAS/STAT ${ }^{\circledR} 9.2$ User's Guide, SAS Institute Inc, Cary, NC, USA, 2008.

[12] H. N. Yarandi, "Crossover designs and Proc Mixed in SAS," in Proceedings of the 12th Annual South East SAS User Group (SESUG) Conference, Nashville, Tenn, USA, October-November 2004.

[13] R. E. McDowell, Importance of Crop Residues for Feeding Livestock in Smallholder Farming Systems, North Carolina State University, Raleigh, NC, USA, 1988.

[14] E. Noah and M. Waitaka, Grain Production in Kenya, Export Processing Zone Authority, Nairobi, Kenya, 2005.

[15] A. J. Heinrichs, D. R. Buckmaster, and B. P. Lammers, "Processing, mixing, and particle size reduction of forages for dairy cattle," Journal of Animal Science, vol. 77, no. 1, pp. 180-186, 1999.

[16] P. J. Kononoff and A. J. Heinrichs, "The effect of reducing alfalfa haylage particle size on cows in early lactation," Journal of Dairy Science, vol. 86, no. 4, pp. 1445-1457, 2003.

[17] D. M. G. Njarui, M. Gatheru, J. M. Wambua, S. N. Nguluu, D. M. Mwangi, and G. A. Keya, "Feeding management for dairy cattle 
in smallholder farming systems of semi-arid tropical Kenya," Livestock Research for Rural Development, vol. 23, article 111, 2011, http://www.lrrd.org/lrrd23/5/njar23111.htm.

[18] T. R. Preston, "Tropical animal feeding. A manual for research workers," FAO Animal Production and Health Paper 126, FAO, Rome, Italy, 1995.

[19] C. Sarnklong, J. W. Cone, W. Pellikaan, and W. H. Hendriks, "Utilization of rice straw and different treatments to improve its feed value for ruminants: a review," Asian-Australasian Journal of Animal Sciences, vol. 23, pp. 680-692, 2010.

[20] O. B. Kashongwe, P. Migwi, B. O. Bebe, P. A. Ooro, T. A. Onyango, and J. O. Osoo, "Improving the nutritive value of wheat straw with urea and yeast culture for dry season feeding of dairy cows," Tropical Animal Health and Production, vol. 46, no. 6, pp. 1009-1014, 2014.

[21] D. A. Teshome, On farm evaluation of urea treated rice straw and rice bran supplementation on feed intake, milk yield and composition of fogera cows, north western Ethiopia [M.S. thesis], Bahir Dahr University, Bahir Dar, Ethiopia, 2009.

[22] S. W. P. Cloete and N. M. Kritzinger, "Urea ammoniation compared to urea supplementation as a method of improving the nutritive value of wheat straw for sheep," Asian-Australasian Journal of Animal Sciences, vol. 14, pp. 59-63, 1984.

[23] P. E. Williams, C. A. Tait, G. M. Innes, and C. J. Newbold, "Effects of the inclusion of yeast culture (Saccharomyces cerevisiae plus growth medium) in the diet of dairy cows on milk yield and forage degradation and fermentation patterns in the rumen of steers," Journal of Animal Science, vol. 69, no. 7, pp. 3016-3026, 1991.

[24] M. Chenost, "Optimizing the use of poor quality roughage through treatments and supplementation in warm climate countries with particular emphasis on urea treatment," in Proceedings of the 1st Electronic Conference on Tropical Feeds with Particular Emphasis on Urea Treatment, FAO, Rome, Italy, 1995.

[25] G. Tingshuang, M. D. Sanchez, and G. P. Yu, Eds., Animal Production Based on Crop Residues. Chinese Experiences, FAO, Rome, Italy, 2002. 


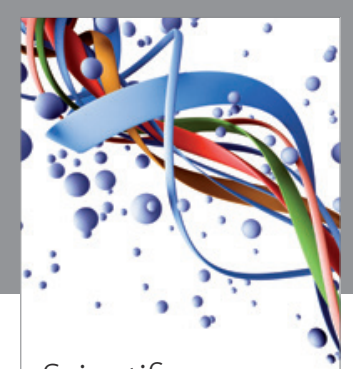

Scientifica
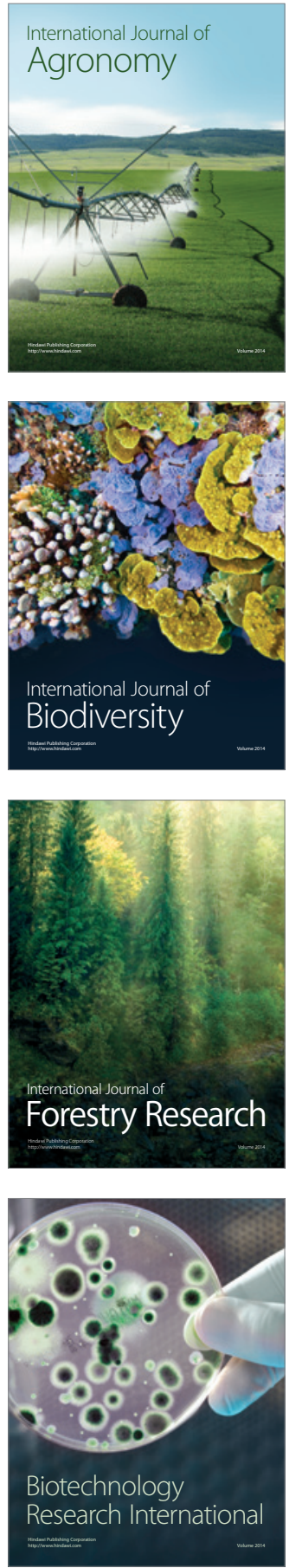
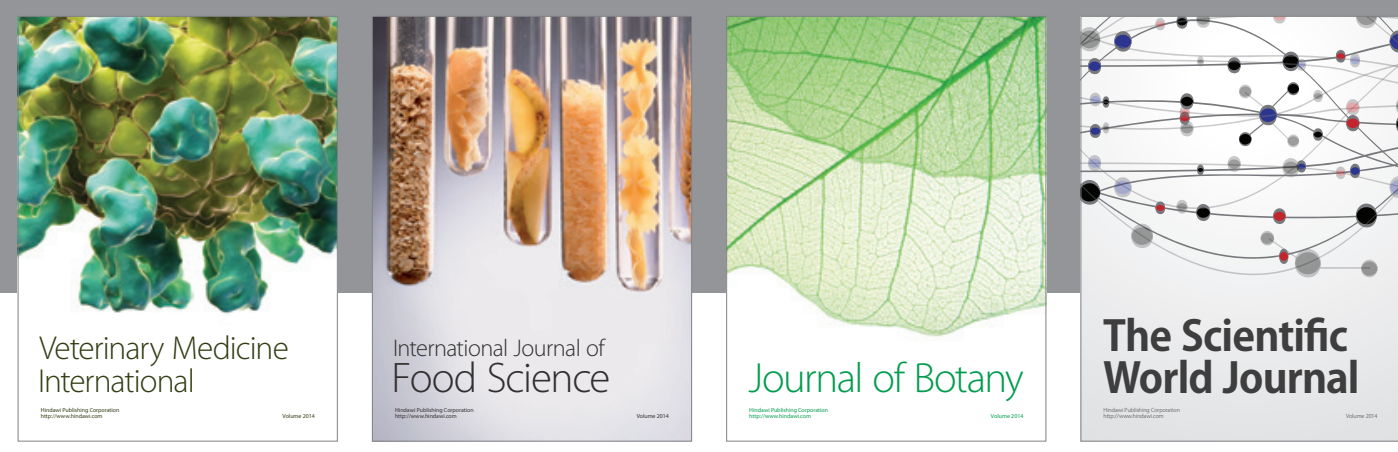

The Scientific

\section{World Journal}

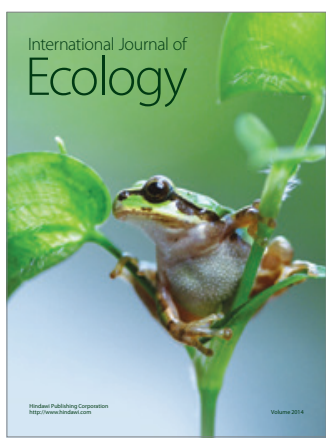

\section{Hindawi}

Submit your manuscripts at

https://www.hindawi.com
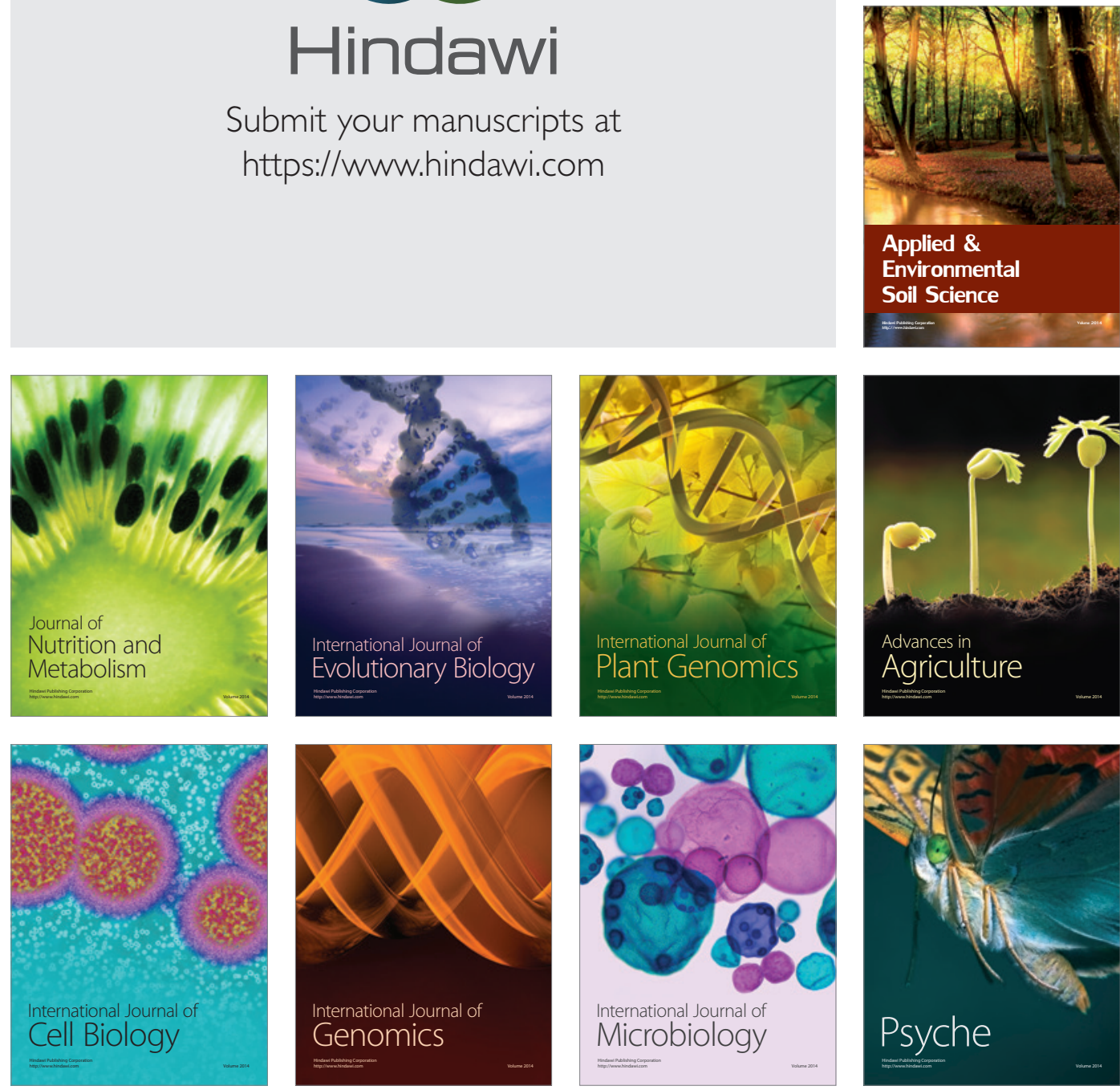
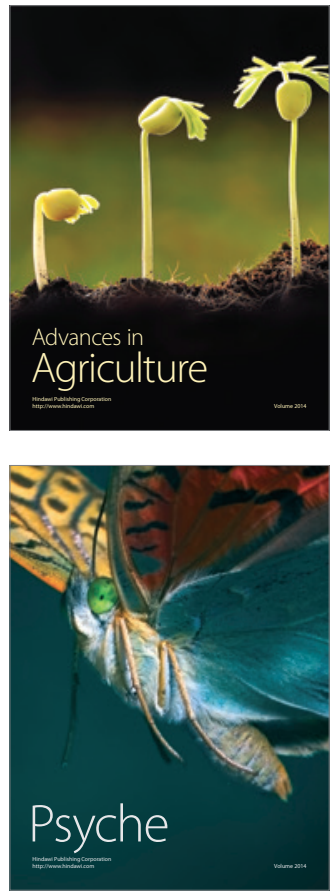